\author{
ARTIGO \\ CO https://doi.org/10.22481/praxisedu.v16i38.6021
}

\title{
DETERMINANTES SOCIAIS E POLÍTICOS DA REGULAMENTAÇÃO E FOMENTO DE CURSOS SUPERIORES DE TECNOLOGIA NO BRASIL
}

\author{
SOCIAL AND POLITICAL DETERMINANTS OF THE REGULATION AND \\ PROMOTION OF TECHNOLOGY HIGHER COURSES IN BRAZIL
}

\author{
DETERMINANTES SOCIALES Y POLÍTICOS DEL REGLAMENTACIÓN Y FOMENTO \\ DE CURSOS SUPERIORES DE TECNOLOGÍA EN BRASIL
}

\author{
José dos Santos Souza \\ Universidade Federal Rural do Rio de Janeiro - Brasil \\ Célia Cristina P. S. Veiga \\ Universidade Federal Rural do Rio de Janeiro - Brasil
}

\begin{abstract}
Resumo: Curso superior de tecnologia (CST), no Brasil, é um tipo de graduação de curta duração, com carga horária mínima de 1.600 a 2.400 horas, dependendo da área, que se insere na categoria de cursos de nível superior na área da educação profissional e tecnológica e confere diploma de tecnólogo. Tomamos como objeto de análise os determinantes sociais, políticos e econômicos do processo de implantação e desenvolvimento deste tipo de curso superior no Brasil. Nosso objetivo é explicitar o papel dos CST na divisão do trabalho educacional do país. Com base em fontes bibliográficas primárias e secundárias, a análise nos evidenciou que este tipo de curso de graduação tem características especiais, pois distinguem-se dos bacharelados e das licenciaturas por serem estruturados para atender diversos setores da economia, abrangendo áreas especializadas, de modo focado no atendimento imediato de demandas do mercado. Assim, esses cursos buscam formar competências profissionais para: a) aplicação, desenvolvimento, pesquisa aplicada e inovação tecnológica, bem como difusão de tecnologias; b) gestão de processos de produção de bens e serviços; e c) desenvolvimento da capacidade empreendedora. Trata-se, portanto, da consolidação definitiva de CST de duração reduzida para formar tecnólogos mais adaptados às condições flexíveis da produção capitalista contemporânea. Esta modalidade de curso de graduação foi implantada a partir do Decreto ${ }^{\circ}$ 2.208/1997, do Governo Fernando Henrique Cardoso. Não obstante, é durante o Governo Lula da Silva que a oferta desse tipo de curso se estende para praticamente toda as redes de educação profissional e tecnológica, sejam elas federal ou estaduais, em decorrência do Decreto $n^{\circ}$ 5.154/2004 e da Lei $n^{\circ} 11.892 / 2008$. Concluímos que, ao final dos anos 2000, os CST passaram a ser uma realidade consolidada, tanto nas redes públicas de educação profissional e tecnológica, quanto na rede privada de ensino superior do Brasil.
\end{abstract}

Palavras-chave: Ensino Superior; Curso Superior de Tecnologia; Educação Tecnológica.

Abstract: Technology Higher Course (THC) in Brazil is a type of short-term graduation, with a minimum workload of 1,600 to 2,400 hours, depending on the area, which falls within the category of higher level courses in the area of vocational and technological education. This type of course confers the technologist diploma. We take as object of analysis the social, political and economic determinants 
of the process of implementation and development of this type of higher education in Brazil. Our purpose is to make explicit the role of this THC in the division of educational work in the country. Based on primary and secondary bibliographic sources, the analysis showed us that this type of undergraduate course has special characteristics, since they are distinguished from other undergraduate degrees because they are structured to serve different sectors of the economy, covering specialized areas, in a focused way in the immediate response to market demands. Thus, these courses seek to form professional skills to: a) application, development, applied research and technological innovation, as well as diffusion of technologies; b) processes management of production of goods and services; and c) development of entrepreneurial capacity. Therefore, it is a definite consolidation of short-term higher education courses to train technologists who are more suited to the flexible conditions of capitalist production in contemporary times. This type of undergraduate course was implemented as of Decree 2.208/1997, from the Fernando Henrique Cardoso Government. Nevertheless, it is during the Lula da Silva Government that the provision of this type of course extends to practically all professional and technological education networks, be they federal or state, as a result of Decree 5.154/2004 and Law 11.892/2008. We conclude that, at the end of the 2000s, THC became a consolidated reality, both in the public networks of professional and technological education, and in the private higher education network in Brazil.

Keywords: Higher Education, Higher Course of Technology, Technological Education.

Resumen: Curso Superior de Tecnología (CST), en Brasil, es un tipo de graduación de corta duración, con carga horaria mínima de 1.600 a 2.400 horas, dependiendo del área, que se inserta en la categoría de cursos de nivel superior en el área de la educación profesional y tecnológica y confiere diploma de tecnólogo. Tomamos como objeto de análisis los determinantes sociales, políticos y económicos del proceso de implantación y desarrollo de este tipo de curso superior en Brasil. Nuestro objetivo es explicitar el papel de los CST en la división del trabajo educativo del país. Con base en fuentes bibliográficas primarias y secundarias, el análisis nos evidenció que este tipo de curso de graduación tiene características especiales, pues se distinguen de los bachilleratos y de las licenciaturas por ser estructurados para atender diversos sectores de la economía, abarcando áreas especializadas, de modo enfocado en la atención inmediata de demandas del mercado. Así, estos cursos buscan formar competencias profesionales para: a) aplicación, desarrollo, investigación aplicada e innovación tecnológica, así como difusión de tecnologías; b) gestión de procesos de producción de bienes y servicios; y c) desarrollo de la capacidad emprendedora. Se trata, por lo tanto, de la consolidación definitiva de cursos superiores de duración reducida para formar tecnólogos más adaptados a las condiciones flexibles de la producción capitalista contemporánea. Esta modalidad de curso de graduación fue implantada a partir del Decreto $n^{\circ}$ 2.208/1997, del Gobierno Fernando Henrique Cardoso. No obstante, es durante el Gobierno de Lula da Silva que la oferta de ese tipo de curso se extiende a prácticamente todas las redes de educación profesional y tecnológica, ya sean federal o estatal, en virtud del Decreto $n^{\circ} 5.154 / 2004$ y de la Ley ${ }^{\circ} 11.892 / 2008$. Concluimos que, al final de los años 2000, los CST pasaron a ser una realidad consolidada, tanto en las redes públicas de educación profesional y tecnológica, como en la red privada de enseñanza superior de Brasil.

Palabras clave: Enseñanza Superior; Curso Superior de Tecnología; Educación Tecnológica.

\section{Curso Superior Enxuto para o Trabalhador Precarizado}

\section{Curso superior de tecnologia, no Brasil, é uma modalidade de curso de nível superior} de curta duração, com carga horária mínima de 1.600 a 2.400 horas, dependendo da área, que se insere na categoria de cursos de graduação na área da educação profissional e tecnológica cujo título conferido é de tecnólogo. Na condição de curso superior com características 
especiais, bem distintos dos tradicionais - embora o acesso se faça por meio de processo seletivo semelhante aos dos demais cursos de graduação -, os cursos superiores de tecnologia devem ser estruturados para atender aos diversos setores da economia, abrangendo áreas especializadas, tendo como foco o atendimento mais imediato de demandas do mercado de trabalho. Segundo o Parecer CNE/CES nº 436/2001 (BRASIL/MEC/CNE, 2001), os egressos desses cursos devem estar aptos a desenvolver atividades em determinada área profissional e devem ter formação específica para: a) aplicação, desenvolvimento, pesquisa aplicada e inovação tecnológica, bem como difusão de tecnologias; b) gestão de processos de produção de bens e serviços; e c) desenvolvimento da capacidade empreendedora (BRASIL, 2001, p. 09). Os portadores de diploma de tecnólogo gozam de todas as prerrogativas legais que qualquer outro graduado em nível superior, podendo ter acesso a cursos de pós-graduação lato sensu e/ou stricto sensu em nível de mestrado profissional ou acadêmico, bem como ao doutorado (Cf.: BRASIL, 2001).

A justificativa recorrente para criação de cursos superiores de tecnologia se baseia em dois argumentos principais. Um é o da necessidade de cursos superiores com duração mais reduzida para atender ao interesse da juventude em dispor de credencial para o mercado de trabalho em tempo mais reduzido; outro é o de que esse tipo de curso permitiria maior rapidez no atendimento às mutações do mercado, ao mesmo tempo em que permite maior aprofundamento em áreas profissionais específicas, em sintonia com o mundo do trabalho. $\mathrm{O}$ Parecer CNE/CES n 436/2001 é bastante claro na crença de que estas características de permanente ligação com o meio produtivo e com supostas necessidades da sociedade "colocam esses cursos em uma excelente perspectiva de atualização, renovação e autorreestruturação, características também inerentes aos cursos sequenciais, porém cada vez mais presentes nos cursos de graduação" (BRASIL/MEC/CNE, 2001, p. 10).

Os cursos superiores de tecnologia atualmente existentes no Brasil têm sua base legal originada no extinto Decreto n ${ }^{\circ}$ 2.208/1997 (BRASIL, 1997, Art. $3^{\circ}$ ), o qual havia estabelecido três níveis para a educação profissional: o básico, o técnico e o tecnológico. Este último correspondia a cursos de nível superior na área tecnológica que deveriam conferir diploma de tecnólogo. O Decreto $n^{\circ}$ 5.154/2004 (BRASIL, 2004), ao revogar o Decreto ${ }^{\circ}$ 2.208/1997, embora mantenha esses mesmos níveis da educação profissional, dá-lhes nova denominação: ao nível básico, denomina de "qualificação profissional, inclusive formação inicial e continuada de trabalhadores"; ao nível técnico, denomina "educação profissional técnica de nível médio"; e ao nível tecnológico, denomina "educação profissional tecnológica de graduação e de pósgraduação”. Neste último nível se inserem os cursos superiores de tecnologia e os mestrados 
profissionais ${ }^{1}$. Como se percebe, o Decreto $\mathrm{n}^{\circ} 5.154 / 2004$ só aprofunda o que o Decreto $\mathrm{n}^{\circ}$ 2.208/1997 havia estabelecido para a educação profissional e tecnológica, ao tornar a nomenclatura mais claramente afinada com os interesses de mercado e ao estender a educação profissional tecnológica até à pós-graduação - algo que não estava explícito no Decreto $\mathrm{n}^{\circ}$ 2.208/1997.

Mas a ideia de implementação de cursos superiores de curta duração com foco nas demandas imediatas do mercado não é uma iniciativa inédita. No início dos anos 1960, o Art. 104 da Lei n 4.024/1961 (BRASIL, 1961) já abria a possibilidade de organização de cursos ou escolas experimentais, com currículos, métodos e períodos escolares próprios, o que se pode considerar como o primeiro passo formal para a criação de cursos superiores diferenciados. Entretanto, segundo Brandão (2007, p. 03), foi a reforma universitária desencadeada pela Lei $\mathrm{n}^{\circ}$ 5.540/1968 (BRASIL, 1968, Art. 18) que deflagrou diversos dispositivos legais, tanto no âmbito federal, quanto no âmbito de diversos estados da federação no sentido de se difundir e implantar cursos superiores de curta duração destinados a proporcionar habilitações profissionais intermediárias mais afinadas com as demandas do mercado.

Brandão (2007, p. 04) aponta que, já na primeira metade dos anos 1960, havia propostas governamentais de implantação de cursos superiores diferentes dos tradicionais e que, em 1962, o Conselho Federal de Educação respaldou uma proposta de criação de uma modalidade distinta de formação de engenheiros para atender especialmente à indústria automobilística. Tratava-se do Curso de Engenharia de Operação, definido como uma formação profissional tecnológica de nível superior com duração de 3 anos.

Durante a década de 1970, esses cursos tiveram grande dificuldade de se afirmarem, em função da resistência das associações de classe dos engenheiros que repudiavam o fato de um profissional formado em curta duração ser chamado de "engenheiro". É somente em 1977 que esta polêmica foi dirimida com a extinção do Curso de Engenharia de Operação e a criação de uma nova modalidade de curso de engenharia, o Curso de Engenharia Industrial, com duração de 5 anos, considerado aceitável para formar engenheiros (BRANDÃO, 2007, p. 07). Apesar de resistências em relação ao título profissional, prevalecia a ideia de necessidade de formação de um profissional mais especializado em uma faixa menor de atividades, capaz de dar respostas mais imediatas a problemas práticos do dia-a-dia da produção. Nessa perspectiva, em 1978,

\footnotetext{
1 A Portaria do Ministério da Educação n 389/2017 (BRASIL/MEC/GABINETE DO MINISTRO, 2017) institui, no âmbito da pós-graduação stricto sensu, a modalidade de doutorado profissional que, junto a de mestrado profissional criada em 1999, funcionam como alternativa de formação profisisonal tecnológica em nível de pósgraduação stricto sensu mais permeável às demandas mercantis, com estrutura curricular e metodologia de ensino distinta dos cursos de pós-graduação stricto sensu de tipo acadêmico.
} 
foram então criados três Centros Federais de Educação Tecnológica (CEFETs) que, dentre outras atribuições, cabia-lhes a tarefa de formar em nível superior profissionais em engenharia industrial (em 5 anos) e tecnólogos (em curta duração). O fato é que, a partir de 1972, se observa no MEC o início de uma política clara de incentivo a cursos superiores de curta duração, não somente na área de engenharia, mas em praticamente todos os setores da economia (NASCIMENTO, 1987 apud BRANDÃO, 2007, p. 7). Segundo Brandão (2007, p. 07), “a partir de então ocorre o verdadeiro impulso para os cursos superiores de curta duração a nível nacional".

Como exemplo de ação governamental para implantação de cursos superiores de curta duração para formar tecnólogos, podemos apontar o que ocorreu em São Paulo em 1968, quando, o governo estadual aciona seu Conselho Estadual de Educação para pronunciar-se a respeito da possibilidade de implantação de cursos de curta duração para formar uma nova modalidade de profissionais. Este episódio resultou na criação do Centro Estadual de Educação Tecnológica Paula Souza (CEET-PS) que, a partir de 1970, manteve a oferta de cursos técnicos de nível superior. Em 1973, o CEET-PS passou a ser instituição mantenedora de diversas Faculdades Tecnológicas Estaduais, por meio das quais passou a organizar seus cursos técnicos de nível superior até meados dos anos 1990, quando os cursos superiores de tecnologia foram instituídos em nível nacional pela reforma da educação profissional desencadeada a partir de 1996.

A consolidação definitiva da proposta de cursos superiores de duração reduzida para formar tecnólogos, sem dúvida, ocorreu a partir do Governo Fernando Henrique Cardoso, especialmente por intermédio da ampliação de vagas para esse tipo de curso na iniciativa privada, referendadas pelo Conselho Nacional de Educação (CNE), que regulamentou a estrutura e o funcionamento dos cursos superiores de tecnologia a partir do Decreto $\mathrm{n}^{\circ}$ 2.208/1997 (BRASIL, 1997). Não obstante, é durante o Governo Lula da Silva que a oferta desses cursos se estende para praticamente toda a Rede Federal de Educação Profissional, Científica e Tecnológica (doravante citada como "Rede Federal") em decorrência do Decreto $n^{\circ} 5.154 / 2004$ (BRASIL, 2004) e da Lei nº 11.892/2008 (BRASIL, 2008b). Ao final dos anos 2000, os cursos superiores de tecnologia passam a ser uma realidade consolidada, tanto na rede pública de ensino - em especial na rede federal e nas redes estaduais de ensino profissional e tecnológico -, quanto na rede privada. 


\section{Raízes Sócio-Históricos da Formação Enxuta do Precariado}

A formação profissional no Brasil2, até o início do processo de industrialização, não era institucionalizada como política pública, sobretudo pela economia primordialmente agroexportadora, com predominância de relações de trabalho rurais arcaicas, baseadas na monocultura, quando a ideia de "profissionalização" estava vinculada, principalmente, à capacitação para o trabalho no campo, de modo que a educação escolar como instituição de formação da força de trabalho ainda não era demandada nem como instrumento de conformação psicofísica do trabalhador nem de conforma ética e moral da sociedade (Cf.: SOUZA, 2002). Todavia, de acordo com Fonseca (1961), em 1906 Nilo Peçanha criou as primeiras escolas profissionais no estado do Rio de Janeiro, por intermédio do Decreto n ${ }^{\circ}$ 787/1906 (RIO DE JANEIRO, 1906 apud FONSECA 1961). Três anos mais tarde, em 1909, quando Nilo Peçanha assumiu a presidência do país, assinou o Decreto $n^{\circ}$ 7.566/1909 (BRASIL, 1909) que cria 19 Escolas de Aprendizes Artífices em diferentes unidades federativas "destinadas ao ensino profissional, primário e gratuito" (BRASIL, 2009, p. 02). São estas escolas profissionalizantes que deram origem à atual Rede Federal.

O período que se estende dos anos 1930 aos anos 1960 é marcado por ações e formulações no campo das políticas públicas para a formação profissional mais contundentes no sentido de promover maior qualificação da força de trabalho para subsidiar o desenvolvimento industrial. Neste período surge o "Sistema S", com a criação do Serviço Nacional de Aprendizagem Industrial (SENAI), em 1942, e o Serviço Nacional de Aprendizagem Comercial (SENAC), em 1946. É também nos anos 1940 que teve início um caloroso e prolongado debate acerca das Lei Diretrizes e Bases da Educação Nacional (LDB), o qual durou treze anos, uma vez que o projeto de Lei apresentado ao Congresso, em 1948, só veio a instituir-se em lei promulgada em 1961 (Lei 4.024/1961). Esta LDB dedica seu Capítulo III ao Ensino Técnico, compreendendo-o como parte orgânica da educação nacional.

O período que se estende desde o Golpe Civil-Militar de 1964 até os anos 1970 foi marcado pelo fato de as políticas públicas para a formação profissional terem assumido caráter mais notadamente alinhado às orientações dos organismos internacionais. Mais precisamente, poderíamos afirmar que foi nesse período em que essas políticas passam a ser mais claramente

\footnotetext{
2 Formação profissional aqui entendida como síntese entre duas dimensões da formação humana no estágio atual do capitalismo, ou seja, a formação profissional no sentido lato, que compreende a Educação Básica, e a formação profissional no sentido stricto, que compreende a Educação Profissional. Esta organicidade entre formação para o trabalho e formação básica está mais bem desenvolvida em Souza (2015, p. 274-275).
} 
condicionadas pela subalternidade do país aos Estados Unidos da América, algo que se expressou nos acordos bilaterais conhecidos como MEC/USAID. É a partir destes acordos que ocorre a reforma da Educação Superior, por intermédio da Lei 5.540/1968, e da Educação Básica, por meio da Lei 5.692/1971 (BRASIL, 1968; 1971). No que tange à Rede Federal, um marco histórico de grande relevo se refere à já mencionada criação dos CEFETs, com a Lei no 6.545/1978 (BRASIL, 1978).

Cerca de 90 anos depois da criação das primeiras Escolas de Aprendizes Artífices, o processo de expansão das políticas públicas para a formação profissional começa a tomar expressão. Nesse período, posterior à redemocratização do país, ocorreu ampla reforma da educação profissional, que desencadeou sua expansão. Em 1997, a Portaria MEC nº 1.005/1997 (BRASIL/MEC, 1997) implementou o Programa de Reforma da Educação Profissional (PROEP) possibilitando operações de crédito com o Banco Interamericano do Desenvolvimento (BID) para esse fim. Tal legislação foi implementada um ano após a promulgação da nova LDB, Lei $\mathrm{n}^{\circ}$ 9.394/1996, e dois anos após a reforma administrativa do aparelho de Estado realizada pelo governo Fernando Henrique Cardoso3 ${ }^{3}$ (BRASIL, 1995; 1996a). Nesse sentido, a própria LDB inicia a contrarreforma4 da Educação Profissional no Brasil. Além disso, logo foi implementado o Decreto $n^{\circ}$ 2.208/1997 (BRASIL, 1997) que estabeleceu as diretrizes para Educação Profissional. Tal legislação regulou os cursos superiores de tecnologia até sua substituição pelo Decreto nº 5.154/2004 (BRASIL, 2004).

Outra política, iniciada no governo de FHC, para formação do trabalhador, foi o Plano Nacional de Qualificação do Trabalhador (PLANFOR), por meio da Resolução n 126/1996 (BRASIL, 1996c), no âmbito do Ministério do Trabalho e Emprego. Essa Resolução prevê a utilização de recursos do Fundo de Amparo do Trabalhador (FAT) para qualificação profissional. Tal medida, além de ampliar o investimento na formação profissional, garante a flexibilização fomentada no bojo da reforma do Estado com vistas à utilização dos recursos públicos.

O processo de reformulação da educação profissional iniciado por FHC teve prosseguimento no governo Lula, com a substituição do Decreto no 2.208/1997 (BRASIL, 1997) pelo Decreto $n^{\circ} 5.154 / 2004$ (BRASIL, 2004) e pela Lei ${ }^{\circ} 11.195 / 2005$ (BRASIL,

\footnotetext{
3 Afiliado do Partido da Social Democracia Brasileiro (PSDB). Seus dois mandatos ocorreram no período de 1995 a 2002.

4 A concepção de contrarreforma denota o processo de reforma antecipada diante de uma provável ação revolucionária ou reivindicatória de uma determinada política, circunstância, fenômeno etc. Nesse sentido, a contrarreforma é uma ação organizada pelo bloco no poder diante da possibilidade de ações da classe trabalhadora.
} 
2005b), que instituiu parceria com organizações não-governamentais para expansão da oferta de educação profissional e regulamentou os cursos superiores de tecnologia ${ }^{5}$. No ano de 2007, Lula instituiu o Programa Brasil Profissionalizado, por meio do Decreto $\mathrm{n}^{\circ}$ 6.302/2007 (BRASIL, 2007a), que dá sequência ao processo de ampliação da educação profissional no país. Ainda no governo de Lula da Silva, foi promulgada a Lei nº 11.892/2008 (BRASIL, 2008b), que instituiu a Rede Federal. Tal Rede é composta por 644 unidades distribuídas entre suas 67 instituições de ensino, são elas: 1) 38 Institutos Federais de Educação, Ciência e Tecnologia; 2) 02 CEFETs; 3) 25 Escolas Técnicas Vinculadas às Universidades Federais; 4) a Universidade Tecnológica Federal do Paraná; e 5) o Colégio Pedro II. Vale ressaltar que, em 2010, essa Rede era composta por 356 unidades e, em 2016, já contabilizavam-se 644 unidades espalhadas pelo território nacional.

O governo Lula da Silva também implementou o Fundo de Financiamento ao Estudante de Ensino Superior (FIES)6, por meio da Lei n 10.260/2001 (BRASIL, 2001b); o Programa Universidade para Todos (PROUNI7), por meio da Lei $\mathrm{n}^{\circ}$ 11.096/2005 (BRASIL, 2005a); o Programa Nacional de Integração da Educação Profissional com a Educação Básica na Modalidade de Educação de Jovens e Adultos (PROEJA) ${ }^{8}$, por meio do Decreto $n^{\circ}$ 5.840/2006 (BRASIL, 2006); e, em 2007, implementou o Plano de Desenvolvimento da Educação (BRASIL/MEC, 2007), que se estabelece como plano executivo do Plano Nacional de Educação (PNE), regulamentado pela Lei nº 10.172/2001 (BRASIL, 2001a).

Nesse sentido, tanto FHC, quanto Lula promoveram a mesma plataforma política para Educação Profissional, a qual foi seguida por Dilma Roussef que, em seu governo, implementou a Lei $n^{\circ}$ 13.005/2014 (BRASIL, 2014b), que institui o PNE 2014-2024; a Lei n ${ }^{\circ} 12.513 / 2011$ (BRASIL, 2011a), que criou o Programa Nacional de Acesso ao Ensino Técnico e Emprego

\footnotetext{
${ }^{5}$ Alterado pelo Decreto $n^{\circ}$ 8.268/2014 (BRASIL, 2014a) e pela Lei no 11.741/2008 (BRASIL, 2008a).

${ }^{6}$ O FIES é o financiamento para conclusão do nível superior em instituições privadas. Por meio dele, o estudante tem a possibilidade de quitar os custos da graduação após sua conclusão, em parcelas acordadas contratualmente com instituição financeira que oferece o programa.

7 O PROUNI é um programa de bolsas de estudos financiadas pelo Estado em instituições de ensino superior privadas para estudantes que, a partir da nota do Exame Nacional do Ensino Médio (ENEM) e critérios socioeconômicos para elegibilidade, concorrem às bolsas integrais e parciais ofertadas nessas instituições.

8 O PROEJA é um programa de integração do ensino profissional com a modalidade de Educação de Jovens e Adultos, no oferecimento de formação técnico-profissional aos estudantes dessa modalidade.
} 
(PRONATEC) $^{9}$; e o Decreto ${ }^{\circ}$ 7.589/2011 (BRASIL, 2011b), que criou a Rede E-Tec Brasil ${ }^{10}$ para desenvolvimento da educação profissional e tecnológica na modalidade à distância (EAD).

Em continuidade ao aprofundamento das reformas educacionais, Michel Temer, presidente do Brasil a partir de 2016, após o impeachment de Dilma Roussef, por meio de Medida Provisória alterou a LDB para implementar o ensino profissional como itinerário formativo no Ensino Médio, por meio da Lei no 13.415/2017 (BRASIL, 2017). Portanto, além da ampliação da formação profissional já evidenciada por meio das políticas públicas relatadas anteriormente, essa última alteração torna cada unidade escolar que possui oferta de Ensino Médio em unidade para formação profissional. Tal fato evidencia a proposta de universalização da formação profissional para classe trabalhadora sob a perspectiva hegemônica. As políticas implementadas para educação profissional compõem, assim, uma grande rede de possibilidades para profissionalização em todos os níveis de formação. Fato que evidencia a pressão política para conformação dos jovens oriundos da classe trabalhadora à condição de ingresso no mundo do trabalho o mais cedo possível. Para isso serve o ensino profissional nos níveis educacionais básicos. E, para aqueles jovens que, porventura, não forem conformados nesse processo, restam os cursos superiores de tecnologia, como uma alternativa aos cursos superiores tradicionais.

A evidência do "favoritismo" político acerca dos cursos superiores de tecnologia em relação aos demais cursos superiores consiste na ampliação da oferta pela criação de novos cursos desde 2006, quando existiam 98 diferentes denominações de cursos. Em 2010, passaram a 113 e, em 2016, existiam 134 diferentes possibilidades de cursos superiores de tecnologia (BRASIL, 2016), o que representa um aumento de 37\% em relação a 2006, só no sistema público de ensino. Além disso, a transferência de recursos para educação profissional é muito superior à transferência de recursos para educação superior, o que demonstra a centralidade da política, sobretudo a partir do governo de Dilma, conforme pode ser observado no Gráfico 1, a seguir. Nesse período, a distância entre os investimentos nas subfunções Ensino Superior e Ensino Profissional aumentou sobremaneira, de modo que os investimentos em Ensino Profissional alcançaram níveis dez vezes superiores àqueles no Ensino superior. Contudo, o ingresso de novos alunos ou mesmo de concluintes não acompanhou os percentuais de aumento no financiamento, com exceção para o ingresso de alunos nos cursos superiores de tecnologia

\footnotetext{
9 O PRONATEC é um programa de expansão da oferta de vagas no ensino profissional aberta a adolescentes, jovens e adultos. Os cursos são oferecidos nas redes pública e privada, nas modalidades presencial e à distância, com financiamento público.

10 A Rede E-Tec Brasil propicia ações de formação inicial e continuada na modalidade EaD, para Formação Inicial ou Continuada ou qualificação profissional; educação profissional de nível médio; educação profissional tecnológica de graduação e pós-graduação; produção de material didático para educação profissional a distância e pesquisas relacionadas com educação a distância. Tais cursos são ofertados pela rede pública de educação.
} 
da rede privada, no ano de 2014, cujo aumento de ingressos foi condizente com o aumento nos repasses financeiros do Governo Federal para a subfunção Ensino Profissional. Indício que requer maior aprofundamento a fim de verificar os destinatários reais desses repasses financeiros, tendo em vista que não estão explícitos no Portal da Transparência do Governo Federal.

\section{GRÁFICO 1: Comparativo entre o financiamento do ensino profissional e ensino superior - série histórica, 2018}
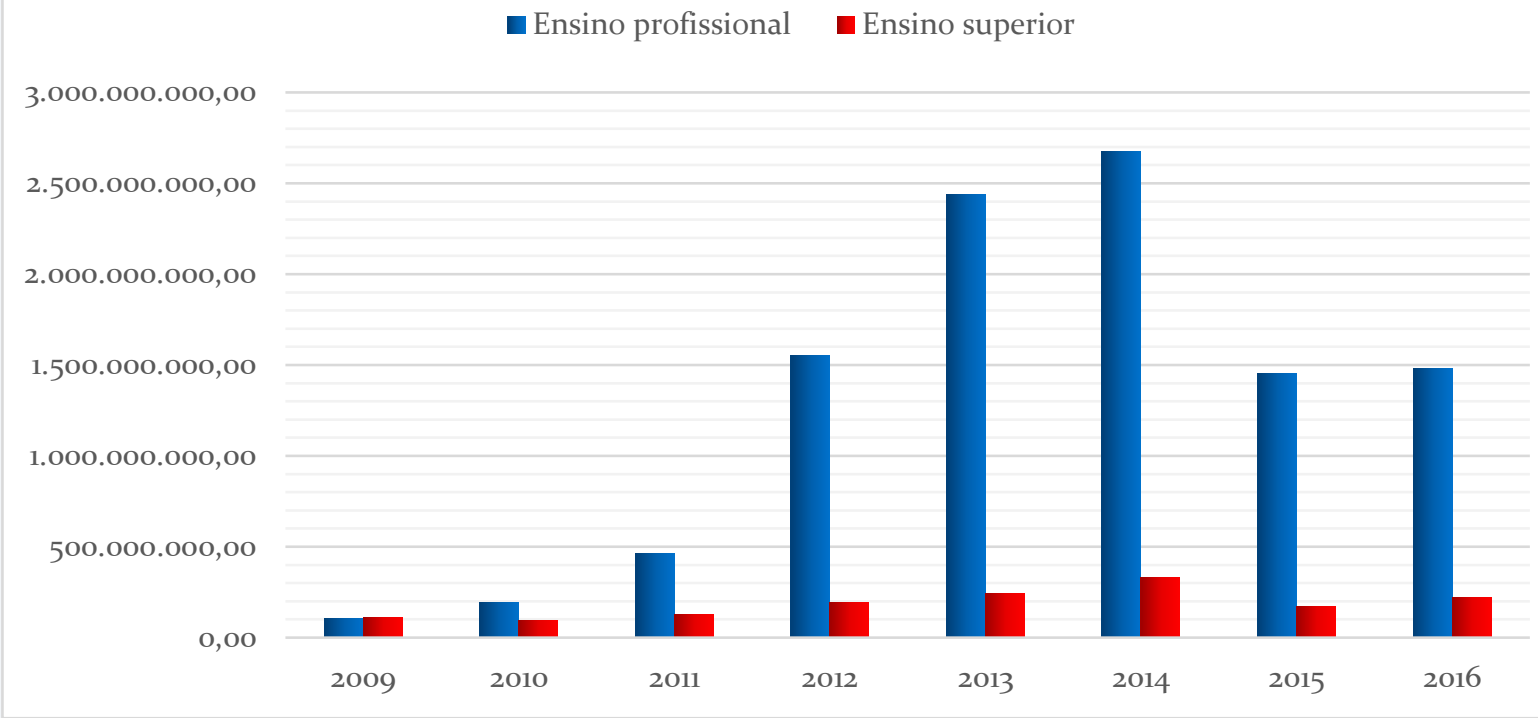

Fonte: Portal da Transparência, elaboração própria.

$\mathrm{Na}$ atual LDB (BRASIL, 1996a), bem como na estrutura institucional do Ministério da Educação brasileiro, está evidente a separação sistêmica entre Educação Profissional Tecnológica e Educação Superior. A educação profissional e tecnológica - na qual estão inseridos os cursos superiores de tecnologia - está a cargo da Secretaria de Educação Profissional e Tecnológica (SETEC), a educação superior está a cargo da Secretaria de Educação Superior (SESu). Além disso, os cursos superiores de tecnologia partem da premissa da "centralidade do trabalho como princípio educativo" 11 - Art. 2, inciso III (BRASIL, 2014a). Os demais cursos superiores, conforme regulamentado no Capítulo IV da Lei ${ }^{\circ}$ 9.394/1996

\footnotetext{
11 Apesar desta referência ao trabalho como príncípio educativo, não há qualquer indício de que as políticas e as práticas educativas emanadas do conjunto de reformas empreendidas caminharam na direção de uma identidade deste discurso com a perspectiva marxista da relação entre trabalho e educação em que o trabalho foi proposto como fundamento político e pedagógico de uma educação emancipatória, de caráter unitário, numa perspectiva omnilateral de formação humana, articulada com a construção de uma nova sociabilidade para além do capital, conforme foram muito bem explicitadas em Gramsci (2001), em Manacorda (2007). Sem estas referências, o discurso do trabalho como princípio educativo contido nos documentos oficiais não ultrapassa os limites do trabalho alienado como fundamento de uma educação flexível, pragmática e imediatamente afinada com as demandas do mercado.
} 
(BRASIL, 1996a), teriam a suposta finalidade de propor uma formação crítica e reflexiva, a partir do desenvolvimento cultural, profissional, científico e político, de modo que capacite para a prática da pesquisa, ensino e extensão, contribuindo para o desenvolvimento da sociedade. Tal fato reforça o histórico dualismo da formação humana no capitalismo: uma formação imediatamente interessada para classe trabalhadora e uma formação desinteressada para classe dominante. Em que pese a crítica acerca da materialização da finalidade dos cursos superiores, é evidente a existência de dois tipos de formação diferentes, desde sua regulamentação legal, para um mesmo nível de ensino. Um curso superior para formação humana - ao menos na proposta - e um curso superior voltado exclusivamente para o trabalho.

A regulamentação dos cursos superiores de tecnologia voltados para atender a demanda de formação da classe trabalhadora, pela denominação de "formação tecnológica", fomenta contradições nesse sentido, tendo em vista a dualidade classista mencionada (MANCEBO; SILVA Jr., 2015). Nesse sentido, a verificação da tecnologia que está sendo ofertada nos cursos superiores de tecnologia é uma demanda para esclarecimento da real materialidade desses cursos. Até porque, uma formação tecnológica aprofundada demandaria tempo de estudo para apropriação do conhecimento. A contradição se apresenta na redução expressiva do tempo desse tipo de curso em relação aos demais cursos de ensino superior.

O tipo de educação realizada em cursos estritamente direcionados ao trabalho pode ser classificado como educação "imediatamente interessada" teorizada por Gramsci (2001). Segundo Souza (2002), a teoria gramsciana parte da existência de três principais tipos de formação: escola do trabalho, desinteressada e desinteressada do trabalho ou escola unitária. A escola do trabalho é orientada para aquisição de conhecimentos técnicos a fim de suprir a demanda de mão-de-obra para o mercado de trabalho. A formação desinteressada é orientada para formação humana idealista, escolástica e fundada na metafísica. Já a formação desinteressada do trabalho ou unitária, segundo esse autor, é "a síntese entre o que há de positivo na escola desinteressada e na escola do trabalho e, por conseguinte, a negação da metafísica inerente à primeira e do pragmatismo inerente à segunda" (SOUZA, 2002, p. 61). Esse último tipo representa o projeto educacional da classe trabalhadora para si própria, visando uma educação omnilateral para emancipação humana.

No contexto em que escreveu sua teoria, na década de 1930, Gramsci já apontava para a tendência de avanço da educação imediatamente interessada:

A tendência atual é a de abolir qualquer tipo de escola "desinteressada" (não imediatamente interessada) e "formativa", ou de conservar apenas um seu reduzido exemplar, destinado a uma pequena elite de senhores e de mulheres 
que não devem pensar em preparar-se para um futuro profissional, bem como a de difundir cada vez mais as escolas profissionais especializadas, mas quais o destino do aluno e sua futura atividade são predeterminados. (GRAMSCI, 2001, p. 33).

E menciona a consequência disso quando afirma que "a multiplicação de tipos de escola profissional, portanto, tende a eternizar as diferenças tradicionais; mas, dado que ela tende, nestas diferenças, a criar estratificações internas, faz nascer a impressão de possuir uma tendência democrática" (GRAMSCI, 2001, p. 49). Nesse sentido, o discurso de promoção da formação profissional é orientado pela máxima de "democratização-universalização", cumprindo o papel de mediação dos conflitos de classes.

A Resolução CNE/CP nº 3/2002 (BRASIL/MEC/CNE, 2002), que define as Diretrizes Curriculares Nacionais Gerais para a Educação Profissional de Nível Tecnológico, deixa clara a natureza imediatamente interessada dos cursos superiores de tecnologia ao estabelecer seus princípios: a) Incentivar o desenvolvimento da capacidade empreendedora e da compreensão do processo tecnológico, em suas causas e efeitos; b) Incentivar a produção e a inovação científico-tecnológica, e suas respectivas aplicações no mundo do trabalho; c) Desenvolver competências profissionais tecnológicas, gerais e específicas, para a gestão de processos e a produção de bens e serviços; d) Propiciar a compreensão e a avaliação dos impactos sociais, econômicos e ambientais resultantes da produção, gestão e incorporação de novas tecnologias; e) Promover a capacidade de continuar aprendendo e de acompanhar as mudanças nas condições do trabalho, bem como propiciar o prosseguimento de estudos em cursos de pósgraduação; f) Adotar a flexibilidade, a interdisciplinaridade, a contextualização e a atualização permanente dos cursos e seus currículos; e, g) Garantir a identidade do Perfil Profissional de conclusão do curso e da respectiva organização curricular.

Por sua natureza imediatamente interessada, tal nível de formação está alinhado com as demandas produtivas. O Parecer CNE/CES n 436/2001 (BRASIL/MEC/CNE, 2001), que regula os cursos superiores de tecnologia, deixa claro que "as novas formas de organização e gestão modificaram estruturalmente o mundo do trabalho" e um "novo cenário econômico e produtivo se estabeleceu com o desenvolvimento e emprego de tecnologias complexas agregadas à produção e à prestação de serviços e pela crescente internacionalização das relações econômicas” (BRASIL, 2001c, p. 1). Essas mudanças impulsionaram os ajustes realizados na Educação Profissional, propondo a regulação dos cursos superiores de tecnologia como nível superior. Portanto, as mudanças impostas pela recomposição burguesa, tanto no campo da 
produção, quanto da reprodução ao demandar de um trabalhador de novo tipo, refletem sobre a Educação Profissional.

\section{A Formação Enxuta do Precarizado e suas Implicações Políticas e Ideológicas}

Na realidade, a política de expansão da Rede Federal elegeu a engenharia institucional dos IFs como modelo, não só por sua afinidade com os propósitos da reforma gerencial na gestão educacional, mas também por sua flexibilidades para colocar em prática a dualidade educacional em condições renovadas. A formação da Rede Federal, portanto, funciona como uma espécie de pedagogia política para a construção do consenso em torno de um projeto político para a educação profissional no Brasil. No bojo dessa pedagogia política, constam conteúdos que buscam resgatar o consenso em torno da legitimidade da livre concorrência, revitalizando-a, na tentativa de estabelecer na sociedade civil um ambiente propício à livre competição entre os indivíduos. Esta pedagogia política se desenvolve por intermédio de apelo à individualidade, ao imediato, aos interesses locais. Constrói-se uma supervalorização à organização corporativa ou de outros tipos de arranjos produtivos locais. Às vezes até na forma de organizações não-governamental, em parceria com o Estado, como forma de valorização do comportamento econômico-corporativo em detrimento da organização da sociedade em torno de interesses políticos de caráter coletivo.

Faz parte desta pedagogia política, também, a disseminação de formas pseudocientíficas de apreensão da realidade social que valorizam o particular, o local, o efêmero, em detrimento de uma compreensão mais objetiva dos elementos que articulam e dão sentido ao Bloco Histórico que comporta as diversas particularidades da vida social, de modo que o próprio critério de cientificidade é flexibilizado, conduzido leituras superficiais da realidade, elucubrações ou mesmo narrativas da vida cotidiana baseada em olhares cada vez mais particulares, fundamentados em absoluto relativismo como argumento metodológico, são conduzidos ao status de ciência.

A partir dessa banalização do fazer científico, ofuscam-se aspectos teóricos e metodológicos de interpretação do fenômeno social, concebendo o pensamento social como mera narrativa especulativa, desprovida de qualquer compromisso de apreensão das contradições que comportam sua concreticidade. Invariavelmente, esse método analítico - ou negação da própria ideia de método - abstém-se de qualquer consideração da totalidade em que o objeto de análise se insere, de modo a atribuir a seu caráter particular, a sua especificidade, absoluto potencial explicativo da realidade, sem qualquer preocupação com as relações que este 
objeto comporta entre si e outros elementos da realidade social. Ao contrário do que Kosik (2010) aponta como dialética do concreto, nessa perspectiva analítica, o conhecimento social se estabelece a partir de sua manifestação fenomênica, onde o olhar particular, desprovido de critério distinto do interesse individual do pesquisador, concebe como "concreto" o que não passa de apreensões imediatas e particulares de determinado objeto, naturalizando determinado fenômeno social em si como uma realidade irrefutável, uma espécie de representação social, uma vez que foi assim percebida pelo seu pensador em de terminado contexto sócio-histórico.

Nessa perspectiva analítica da nova pedagogia política do capital, a naturalização da ideologia da "mão invisível do mercado" como reguladora eficiente do cotidiano social se apresenta como uma realidade naturalizada, de modo que qualquer especulação que lhe atribua relações com outros elementos da realidade, como por exemplo, a precarização do trabalho, é imediatamente rechaçada. De modo geral, esta pedagogia política constitui o mecanismo pelo qual a burguesia busca formar as competências necessárias à conformação ético e moral dos trabalhadores em uma dinâmica renovada de construção do consenso em torno da concepção de mundo burguesa, consolidando-se, assim, no meio social, por meio da naturalização da lógica de mercado, a subsunção real do trabalho ao capital.

A necessidade estrutural do estágio atual de desenvolvimento do capital de ampliar mesmo que de forma ainda limitada - as oportunidades de acesso ao conhecimento para uma parcela restrita da classe trabalhadora, necessariamente, se justificam na sociedade civil por meio de um discurso integrador de defesa da universalização da Educação Básica, ampliação das oportunidades de Educação Profissional, inclusão social de jovens e combate ao trabalho infantil. Mas este discurso é, de fato, uma ilusão necessária à manutenção do monopólio do conhecimento. Por meio desta ilusão, a burguesia controla o acesso ao conhecimento científico e tecnológico aplicado na produção, promovendo diferentes tipos de formação para a classe trabalhadora. É inerente a este fenômeno a ocorrência da dualidade entre formação para o trabalho intelectual - destinado a uma elite da classe trabalhadora - e formação para o trabalho manual - destinado à grande maioria dos trabalhadores.

Esse contexto exige não só a formação de trabalhadores de novo tipo, mais adaptados às novas demandas do mundo do trabalho, mas também a sua conformação ética e moral para assimilar com naturalidade a instabilidade e a completa vulnerabilidade da vida. Nesse aspecto, a estruturação da Rede Federal, com a criação dos IFs, assume caráter estratégico importante, não só para alimentar as empresas com trabalhadores mais flexíveis e suficientemente competitivos, mas também para conformar o imenso contingente de trabalhadores excluídos do 
mercado formal de emprego para encarar com naturalidade a precariedade social do trabalho que esta realidade lhes impõe.

Dialeticamente, é exatamente na incapacidade da política pública de formação humana da ordem burguesa para cumprir seu propósito de socializar o conhecimento científico e tecnológico necessário para o trabalho e para a vida em sociedade, ainda que de modo fragmentado e numa perspectiva dualista, o que constitui o elemento positivo para a organização e luta dos trabalhadores contra o capital, contra o monopólio do conhecimento. ${ }^{12}$ Tal positividade consiste exatamente no fato de que essa incapacidade do capital, na medida em que se evidencia nas contradições de suas políticas públicas de formação humana, abre amplas possibilidades de mobilização da classe trabalhadora, ao mesmo tempo em que desmascara a pedagogia política do capital para conformá-los na sua condição de vida precária.

Devido à incapacidade do padrão compósito vigente garantir emprego, seguridade social e inclusão social, já que sua preocupação é reorientar o uso do fundo público para garantir estabilidade financeira ao grande capital, o tipo de formação humana destinado aos filhos da classe trabalhadora ganha contornos ainda mais perversos, pois cabe-lhe também conformar ética e moralmente um número considerável de jovens e adultos fadados ao desemprego, à informalidade, ao contrato precário de trabalho (estágios, emprego temporário etc.), condenados à condição de vulnerabilidade permanente. Assim, a formação humana destinada a eles radicaliza cada vez mais sua função política de mediação do conflito de classes por meio da pedagogia política que visa naturalizar a intensificação da precariedade da vida no estágio atual do capitalismo. Para isto, aciona reformas curriculares que priorizam determinados conhecimentos fragmentados e determinados conteúdos que não passam de apologia à legitimação do desenvolvimento (in)sustentável, à competitividade mercantil, ao individualismo, ao empreendedorismo e à empregabilidade. Nesse propósito, a estruturação da Rede Federal, somada a diversos outros mecanismos de ampliação da oferta de educação profissional, é fundamental.

Nestes termos desenvolve-se a contrarreforma burguesa da Educação Profissional para atender às novas demandas de formação/qualificação do trabalhador brasileiro. Em linhas gerais, ela pode ser definida como um conjunto de mudanças no planejamento e gestão

12 Para a compreensão objetiva deste contexto, a teoria do Estado formulada por Gramsci (1989; 2008) é providencial, na medida em que incorpora o conceito de hegemonia e amplia a concepção de Estado, concebendoo como resultado da condensação de forças políticas em disputa na sociedade civil. De acordo com esse quadro analítico gramsciano, o aspecto dialético do desenvolvimento das políticas públicas para a formação humana na ordem burguesa de produção e reprodução social da vida material ganha mais clareza, a ponto de ver nelas alguma possibilidade de ação contra hegemônica e nos permitir enxergar elementos que, frequentemente, as análises acerca da ação pública no campo da formação humana não consideram. 
educacional e nos processos pedagógicos que se estendeu desde o Governo FHC, passando pelo Governo Lula da Silva, tendo continuidade no Governo Dilma Rousseff, provocando mudanças substantivas no trabalho educativo realizado pelas instituições da Rede Federal. No decurso desta contrarreforma, fica evidente o esforço do empresariado e do Estado para conferir ao trabalho pedagógico um caráter mais "interessado", preocupados em atender de forma mais imediata às demandas de produtividade e competitividade das empresas.

Nessa perspectiva, a concepção da relação entre ciência e vida, entre trabalho e educação, entre empresa e escola que passa a predominar na gestão do trabalho escolar ganha um caráter mais pragmático, mais de acordo com a lógica mercantil, mais coerente com os princípios neoliberais de competitividade como fator de qualidade, conforme as indicações de Friedman (1985) e de Mello (2005), dentre outros. Obviamente, essas ideias, na medida em que passam a dar direção à vida cotidiana das instituições componentes da Rede Federal, provocam certo reordenamento dos princípios éticos e morais que norteiam seu trabalho escolar, dando novos significados às relações pedagógicas e políticas ocorridas no cotidiano dos IFs e demais instituições de ensino que a compõem, de modo a instituir certa mudança na cultura dessas escolas, com o intuito de conservar, em condições renovadas, o potencial dessas instituições como espaço privilegiado de mediação do conflito de classes e de propagação do consenso em torno da concepção de mundo burguesa. Assim, em um contexto de reestruturação produtiva e de reforma do Estado, a gestão do trabalho escolar das instituições de ensino da Rede Federal é reconfigurada de modo a garantir, nas condições objetivas e subjetivas da conjuntura atual, a manutenção de seu papel como aparelho privado de hegemonia burguesa.

Tendo que lidar com a contradição de ter que formar técnicos especializados para operar o maquinário avançado das empresas reestruturadas na atualidade, desde meados dos anos 1980, o empresariado brasileiro vem empreendendo esforços para, de um lado flexibilizar o fluxo e os conteúdos dos currículos para formar com maior rapidez e com menor custo a força de trabalho necessária para executar tanto o trabalho simples como o trabalho complexo. Flexibilizando também o Ensino Superior, as iniciativas de redução da duração de cursos para atender mais imediatamente às demandas do mercado ganha materialidade na criação dos Cursos Superiores de Tecnologia, durante o Governo FHC, amplamente explorados por instituições privadas de ensino, ávidas por explorar o mais novo filão do mercado educacional: um contingente considerável de trabalhadores interessados em fazer curso superior de curta duração e conquistar a tão propagada empregabilidade o mais rápido possível. Com a oferta de cursos que poderiam ser concluídos em no máximo dois anos, com mensalidades a baixo custo, 
esse tipo de curso mobilizou e ainda mobiliza muitos jovens trabalhadores, alimentando o mercado educacional.

Esta flexibilização do Ensino Superior só atingiu o setor público de ensino a partir do Governo Lula da Silva, o qual aperfeiçoou consideravelmente a ofensiva do Estado sobre a política educacional. Pode-se dizer que o Governo Lula da Silva concretizou praticamente tudo que o Governo FHC não havia conseguido concretizar no que diz respeito à flexibilização dos sistemas de ensino para atender mais imediatamente às demandas empresariais. Este feito se deve ao amplo apoio popular de que gozava este governo, inclusive do movimento organizado dos servidores públicos federais. Neste movimento, o governo avança na reforma da Educação Profissional, com o Decreto $n^{\circ}$ 5.154/2004, em substituição ao Decreto $n^{\circ}$ 2.208/1997 (BRASIL, 1997; 2004); amplia o condicionamento do financiamento da educação à accountabillity dos sistemas educacionais para toda a Educação Básica, com a Lei $\mathrm{n}^{\circ}$ 11.494/2007 (BRASIL, 2007b), em substituição da Lei nº 9.424/1996 (BRASIL, 1996b); institui a Rede Federal, com a Lei n ${ }^{\circ}$ 11.892/2008 (BRASIL, 2008b); organiza o desenvolvimento de Cursos Superiores de Tecnologia, com a criação Catálogo Nacional dos Cursos Superiores de Tecnologia; fomenta a reengenharia institucional da educação profissional nas redes estaduais, promovendo a separação da gestão da Educação Básica da gestão da Educação Profissional, induzindo a criação de redes de ensino profissional e tecnológico em todos os estados da federação por meio de programas especiais de investimentos em infraestrutura física e financiamentos; aperfeiçoa a política pública de trabalho, qualificação e renda, ampliando as parcerias públicoprivadas e promovendo reforma gerenciais na gestão dos órgãos envolvidos.

\section{Conclusão}

A articulação da Rede Federal - que tem nos IFs sua principal referência de engenharia institucional para a promoção da ampliação da oferta de educação profissional - cumpre papel importante no processo de recomposição burguesa frente a crise orgânica do capital. Essa Rede de ensino acaba por instituir a flexibilidade necessária para que a política pública de formação profissional possa cumprir de modo eficiente sua dupla função, ofertando em um mesmo tipo de instituição todos os tipos e modalidades de formação humana interessada, seja para atender objetivamente as demandas do mercado, seja para conformar amplo contingente de trabalhadores jovens fadados ao desemprego e à informalidade do trabalho, por meio dos princípios do empreendedorismo, do desenvolvimento sustentável e da empregabilidade. 


\section{REFERÊNCIAS}

BRANDÃO, Marisa. Cursos superiores de tecnologia: democratização do acesso ao ensino superior? Trabalho Necessário, Ano V, No 05, p. 1-15, 2007.

BRASIL. Decreto no 7.566, de 23 de setembro de 1909. Créa nas capitaes dos Estados da Escolas de Aprendizes Artífices, para o ensino profissional primario e gratuito. Rio de Janeiro (DF): Rio de Janeiro: 1909. Disponível em: http://portal.mec.gov.br/setec/arquivos/pdf3/decreto_7566_1909.pdf , acesso em 23/07/2019.

BRASIL. Decreto-lei no 4.048, de 22 de janeiro de 1942. Cria o Serviço Nacional de Aprendizagem dos Industriários (SENAI). Rio de Janeiro (DF): 1942. Disponível em: https://www2.camara.leg.br/legin/fed/declei/1940-1949/decreto-lei-4048-22-janeiro-1942414390-publicacaooriginal-1-pe.html, Acesso em 23/07/2019

BRASIL. Decreto-lei no 8.621, de 10 de janeiro de 1946. Dispõe sobre a criação do Serviço Nacional de Aprendizagem Comercial e dá outras providências. Rio de Janeiro (DF): 1946. Disponível em: http://www.planalto.gov.br/ccivil_03/Decreto-Lei/1937-1946/Del8621.htm, acesso em 23/07/2019.

BRASIL. Lei no 4.024, de 20 de dezembro de 1961. Fixa as Diretrizes e Bases da Educação Nacional. Brasília (DF): 1961. Disponível em: http://www.planalto.gov.br/ccivil_03/leis/L4024.htm, acesso em 23/07/2019.

BRASIL. Lei $\mathbf{n}^{0}$ 5.540, de 28 de novembro de 1968. Fixa normas de organização e funcionamento do ensino superior e sua articulação com a escola média, e dá outras providências. Brasília: 1968. Disponível em:

http://www.planalto.gov.br/ccivil_03/leis/L5540.htm, acesso em 23/07/2019.

BRASIL. Lei $\mathbf{n}^{0}$ 9.394, de 20 de dezembro de 1996. Estabelece as diretrizes e bases da educação nacional. Brasília, DF, 1996a. Disponível em:

<http://www.planalto.gov.br/ccivil_03/leis/L9394.htm>. Acesso em: 23/07/2019.

BRASIL. Lei $\mathbf{n}^{\circ}$ 9.424, de 24 de dezembro de 1996. Dispõe sobre o Fundo de Manutenção e Desenvolvimento do Ensino Fundamental e de Valorização do Magistério, na forma prevista no art. $60, \S 7^{\circ}$, do Ato das Disposições Constitucionais Transitórias, e dá outras providências. Brasília (DF): 1996b. Disponível em: http://www.planalto.gov.br/ccivil_03/LEIS/L9424.htm , acesso em 23/07/2019.

BRASIL. Resolução n $\mathbf{n}^{\mathbf{0}}$ 126, de 23 outubro de 1996. Aprova critérios para a utilização de recursos do Fundo de Amparo ao Trabalhador - FAT, pela Secretaria de Formação e

Desenvolvimento Profissional - SEFOR, com vistas à execução de ações de qualificação e requalificação profissional, no âmbito do Programa do Seguro-Desemprego, no período de 1997/1999. Brasília (DF): 1996c. Disponível em:

http://portal.mec.gov.br/cne/arquivos/pdf/CES0436.pdf , acesso em 23/07/2019

BRASIL. Decreto $\mathbf{n}^{\mathbf{0}} \mathbf{2 . 2 0 8}$, de 17 de abril de 1997. Regulamenta o $§ 2^{\circ}$ do art. 36 e os Arts. 39 a 42 da Lei $n^{\circ} 9.394$, de 20 de dezembro de 1996, que estabelece as diretrizes e bases da educação nacional. Brasília: 1997. Disponível em:

http://www.planalto.gov.br/ccivil_03/decreto/d2208.htm , acesso em 23/07/2019. 
BRASIL. Lei no 10.172, de 9 de janeiro de 2001. Aprova o Plano Nacional de Educação e dá outras providências. Brasília (DF): 2001a. Disponível em: http://www.planalto.gov.br/ccivil_03/leis/leis_2001/110172.htm , acesso em 23/07/2019.

BRASIL. Lei no 10.260, de 12 de julho de 2001. Dispõe sobre o Fundo de Financiamento ao Estudante do Ensino Superior e dá outras providências. Brasília (DF): 2001b. Disponível em: https://www2.camara.leg.br/legin/fed/lei/2001/lei-10260-12-julho-2001-329619publicacaooriginal-1-pl.html , acesso em 23/07/2019.

BRASIL. Decreto $n^{0}$ 5.154, de 23 de julho de 2004. Regulamenta o $\S 2^{\circ}$ do art. 36 e os arts. 39 a 41 da Lei n $^{\circ}$ 9.394, de 20 de dezembro de 1996, que estabelece as diretrizes e bases da educação nacional, e dá outras providências. Brasília: 2004. Disponível em: http://www.planalto.gov.br/ccivil_03/_ato2004-2006/2004/decreto/d5154.htm, acesso em 23/07/2019.

BRASIL. Lei $\mathbf{n}^{\mathbf{0}}$ 11.096, de 13 de janeiro de 2005. Institui o Programa Universidade para Todos - PROUNI, regula a atuação de entidades beneficentes de assistência social no ensino superior; altera a Lei $\mathrm{n}^{\mathrm{o}} 10.891$, de 9 de julho de 2004, e dá outras providências. Brasília (DF): 2005a. Disponível em: https://www2.camara.leg.br/legin/fed/lei/2005/lei-11096-13-janeiro2005-535381-normaatualizada-pl.html , acesso em 23/07/2019.

BRASIL. Lei $\mathbf{n}^{\circ} \mathbf{1 1 . 1 9 5}$, de 18 de novembro de 2005. Dá nova redação ao $\S 5^{\circ}$ do art. $3^{\circ}$ da Lei ${ }^{\circ} 8.948$, de 8 de dezembro de 1994. Brasília (DF): 2005b. Disponível em: http://www.planalto.gov.br/ccivil_03/_Ato2004-2006/2005/Lei/L11195.htm, acesso em 23/07/2017.

BRASIL. Decreto $\mathbf{n}^{0}$ 5.840, de 13 de julho de 2006. Institui, no âmbito federal, o Programa Nacional de Integração da Educação Profissional com a Educação Básica na Modalidade de Educação de Jovens e Adultos - PROEJA, e dá outras providências. Brasília (DF): 2006.

Disponível em: http://www.planalto.gov.br/ccivil_03/_ato20042006/2006/decreto/d5840.htm, acesso em 23/07/2019.

BRASIL. Decreto $\mathbf{n}^{\mathbf{0}}$ 6.302, de 12 de dezembro de 2007. Institui o Programa Brasil Profissionalizado. Brasília (DF): 2007a. Disponível em: http://www.planalto.gov.br/ccivil_03/_Ato2007-2010/2007/Decreto/D6302.htm, acesso em 23/07/2019.

BRASIL. Lei n⿳ 11.494, de 20 de junho de 2007. Regulamenta o Fundo de Manutenção e Desenvolvimento da Educação Básica e de Valorização dos Profissionais da Educação FUNDEB, de que trata o art. 60 do Ato das Disposições Constitucionais Transitórias; altera a Lei no 10.195, de 14 de fevereiro de 2001; revoga dispositivos das Leis nos 9.424, de 24 de dezembro de 1996, 10.880, de 9 de junho de 2004, e 10.845, de 5 de março de 2004; e dá outras providências. Brasília (DF): 2007b. Disponível em: http://www.planalto.gov.br/ccivil_03/_ato2007-2010/2007/lei/111494.htm , acesso em 23/07/2019.

BRASIL. Lei $\mathbf{n}^{\mathbf{0}}$ 11.741, de 16 de julho de 2008. Altera dispositivos da Lei no 9.394, de 20 de dezembro de 1996, que estabelece as diretrizes e bases da educação nacional, para redimensionar, institucionalizar e integrar as ações da educação profissional técnica de nível médio, da educação de jovens e adultos e da educação profissional e tecnológica. Brasília 
(DF): 2008a. Disponível em: https://www.planalto.gov.br/ccivil_03/_Ato20072010/2008/Lei/L11741.htm\#art1, acesso em 23/07/2019.

BRASIL. Lei no 11.892, de 29 de dezembro de 2008. Institui a Rede Federal de Educação Profissional, Científica e Tecnológica, cria os Institutos Federais de Educação, Ciência e Tecnologia, e dá outras providências. Brasília (DF): 2008b. Disponível em: http://www.planalto.gov.br/ccivil_03/_ato2007-2010/2008/lei/111892.htm , acesso em 23/07/2019.

BRASIL. Lei $\mathbf{n}^{\mathbf{0}}$ 12.513, de 26 de outubro de 2011. Institui o Programa Nacional de Acesso ao Ensino Técnico e Emprego (Pronatec); altera as Leis nº 7.998, de 11 de janeiro de 1990, que regula o Programa do Seguro-Desemprego, o Abono Salarial e institui o Fundo de Amparo ao Trabalhador (FAT), no 8.212, de 24 de julho de 1991, que dispõe sobre a organização da Seguridade Social e institui Plano de Custeio, ${ }^{\circ} 10.260$, de 12 de julho de 2001, que dispõe sobre o Fundo de Financiamento ao Estudante do Ensino Superior, e $n^{\circ}$ 11.129, de 30 de junho de 2005, que institui o Programa Nacional de Inclusão de Jovens (ProJovem); e dá outras providências. Brasília (DF): 2011a. Disponível em: http://www.planalto.gov.br/ccivil_03/_ato2011-2014/2011/lei/112513.htm, acesso em 23/07/2019.

BRASIL. Decreto n 7.589, de 26 de outubro de 2011. Institui a Rede e-Tec Brasil. Brasília (DF): 2011b. Disponível em: http://www.planalto.gov.br/ccivil_03/_Ato20112014/2011/Decreto/D7589.htm, acesso em 23/07/2019.

BRASIL. Decreto $\mathbf{n}^{\mathbf{0}} \mathbf{8 . 2 6 8}$, de 18 de junho de 2014. Altera o Decreto ${ }^{\circ} 5.154$, de 23 de julho de 2004, que regulamenta o $\S 2^{\circ}$ do art. 36 e os arts. 39 a 41 da Lei $n^{\circ} 9.394$, de 20 de dezembro de 1996. Brasília (DF): 2014a. Disponível em:

http://www.planalto.gov.br/ccivil_03/_Ato2011-2014/2014/Decreto/D8268.htm , a acesso em 23/07/2019.

BRASIL. Lei no 13.005, de 25 de junho de 2014. Aprova o Plano Nacional de Educação PNE e dá outras providências. Brasília (DF): 2014b. Disponível em: http://www.planalto.gov.br/ccivil_03/_ato2011-2014/2014/lei/113005.htm , acesso em 23/07/2019.

BRASIL. Lei $\mathbf{n}^{\circ}$ 13.415, de 16 de fevereiro de 2017. Altera as Leis $n^{\circ} 9.394$, de 20 de dezembro de 1996, que estabelece as diretrizes e bases da educação nacional, e 11.494, de 20 de junho 2007, que regulamenta o Fundo de Manutenção e Desenvolvimento da Educação Básica e de Valorização dos Profissionais da Educação, a Consolidação das Leis do Trabalho - CLT, aprovada pelo Decreto-Lei $n^{\circ} 5.452$, de $1^{\circ}$ de maio de 1943, e o Decreto-Lei $n^{\circ} 236$, de 28 de fevereiro de 1967; revoga a Lei $n^{\circ}$ 11.161, de 5 de agosto de 2005; e institui a Política de Fomento à Implementação de Escolas de Ensino Médio em Tempo Integral. Brasília (DF): 2017. Disponível em: http://www.planalto.gov.br/ccivil_03/Ato20152018/2017/Lei/L13415.htm, acesso em 23/07/2019.

BRASIL. MINISTÉRIO DA EDUCAÇÃO E DESPORTO. Portaria no $\mathbf{1 . 0 0 5}$, de 10 de setembro de 1997. Institui, no âmbito da Secretaria de Educação Média e Tecnológica (SEMTEC), a Unidade de Coordenação do Programa (UCP), incumbida de adotar as providências necessárias à implementação do PROEP. Brasília (DF): 1997. Disponível em: http://portal.mec.gov.br/setec/arquivos/pdf/Port1005.pdf , acesso em 23/07/2019. 
BRASIL. MINISTÉRIO DA EDUCAÇÃO. Centenário da rede federal de educação profissional e tecnológica. Brasília (DF): MEC, 2009. 8 p. Disponível em:

http://portal.mec.gov.br/setec/arquivos/centenario/historico_educacao_profissional.pdf , acesso em 23/07/2019.

BRASIL. MINISTÉRIO DA EDUCAÇÃO. CONSELHO NACIONAL DE EDUCAÇÃO. CÂMARA DE EDUCAÇÃO SUPERIOR. Parecer n⿳ 436, de 02 de abril de

2001. Assunto: cursos superiores de tecnologia - formação de tecnólogos. Brasília (DF): 2001. Disponível em: http://portal.mec.gov.br/cne/arquivos/pdf/CES0436.pdf , acesso em 23/07/2019.

BRASIL. MINISTÉRIO DA EDUCAÇÃO. CONSELHO NACIONAL DE EDUCAÇÃO. CONSELHO PLENO. Resolução CNE/CP nº 03, de 18 de dezembro de 2002. Institui as Diretrizes Curriculares Nacionais Gerais para a organização e o funcionamento dos cursos superiores de tecnologia. Brasília (DF): 2002. Disponível em: http://portal.mec.gov.br/cne/arquivos/pdf/CP032002.pdf , acesso em 23/07/2019.

BRASIL. MINISTÉRIO DA EDUCAÇÃO. GABINETE DO MINISTRO. Portaria n 389, de 23 de março de 2017. Dispõe sobre o mestrado e doutorado profissional no âmbito da pós-graduação stricto sensu. Brasília (DF): 2017. Disponível em:

http://www.in.gov.br/materia/-/asset_publisher/Kujrw0TZC2Mb/content/id/20482828/do12017-03-24-portaria-no-389-de-23-de-marco-de-2017-20482789 , acesso em 23/07/2019.

BRASIL. MINISTÉRIO DA EDUCAÇÃO. O plano de desenvolvimento da educação: razões, princípios e programas. Brasília (DF): MEC, 2007. 43 p.

BRASIL. MINISTÉRIO DA EDUCAÇÃO. SECRETARIA DE REGULAÇÃO E SUPERVISÃO DA EDUCAÇÃO SUPERIOR. SECRETARIA DE EDUCAÇÃO PROFISSIONAL E TECNOLÓGICA. Catálogo Nacional de Cursos Superiores de Tecnologia. $3^{\text {a }}$ Ed. Brasília (DF): MEC, 2016. 194 p.

BRASIL. PRESIDÊNCIA DA REPÚBLICA. CAMARA DA REFORMA DO ESTADO. Plano Diretor da Reforma do Aparelho do Estado. Brasília (DF): 1995. Disponível em: http://www.bresserpereira.org.br/documents/mare/planodiretor/planodiretor.pdf , acesso em 23/07/2019.

FONSECA, Celso Suckow. História do Ensino Industrial no Brasil. Rio de Janeiro: SENAI, 1961. Vol. 1.

FRIEDMAN, Milton. Capitalismo e liberdade. Tradução de Luciana Carli. $2^{\mathrm{a}}$ Ed. São Paulo: Nova Cultural, 1985. 187 p.

GRAMSCI, Antonio. Americanismo e fordismo. São Paulo: Hedra, 2008. 92 p.

GRAMSCI, Antonio. Cadernos do cárcere. Tradução de Carlos Nelson Coutinho. $2^{\mathrm{a}}$. ed. Rio de Janeiro: Civilização Brasileira, 2001. Vol II, 334 p.

GRAMSCI, Antonio. Maquiavel, a política e o Estado moderno. Rio de Janeiro: Civilização Brasileira, 1989. 446 p. 
KOSIK, Karel. Dialética do concreto. Trad.Célia Neves e Alderico Toríbio. Rio de Janeiro: Paz e Terra, 2010. 250 p.

MANACORDA, Mario Alighiero. Marx e a pedagogia moderna. Tradução Newton Ramosde-Oliveira. Campinas (SP): Alínea, 2007. 206 p.

MANCEBO, Deise; SILVA Jr., João dos Reis. Expansão da educação superior e a reforma da rede federal de educação profissional. Revista Educação em Questão, Natal, v. 51, n. 37, p. 73-94, jan./abr. 2015.

MELLO, Guiomar Namo de. Cidadania e competitividade: desafios educacionais do terceiro milênio. 10ª Ed. São Paulo: Cortez, 2005. 204 p.

SOUZA, José dos Santos. Trabalho, Educação e sindicalismo no Brasil: anos 90.

Campinas, SP: Autores Associados, 2002. 244 p.

SOUZA, José dos Santos. A formação do trabalhador no contexto da reconfiguração do trabalho, da produção e dos mecanismos de mediação do conflito de classe. Revista

Contemporânea de Educação, vol. 10, n. 20, p. 273-290, julho/dezembro de 2015.

\section{SOBRE OS AUTORES:}

\section{José dos Santos Souza}

Doutor em Sociologia pelo Instituto de Filosofia e Ciências Humanas da Universidade Estadual de Campinas (UNICAMP), com Pós-doutorado em Educação pela Faculdade de Educação da UNICAMP. Atua como Professor Associado III do Departamento de Educação e Sociedade do Instituto Multidisciplinar da UFRRJ, onde integra o quadro docente do Programa de PósGraduação em Educação, Contextos Contemporâneos e Demandas Populares (PPGEduc) e lidera o Grupo de Pesquisas Sobre Trabalho, Política e Sociedade (GTPS). E-mail: jsantos@ufrrj.br

(iD http://orcid.org/0000-0001-5433-0812

\section{Célia Cristina P. S. Veiga}

Doutoranda em Educação pela Programa de Pós-Graduação em Educação, Contextos Contemporâneos e Demandas Populares (PPGEduc). É membro do Grupo de Pesquisas Sobre Trabalho, Política e Sociedade (GTPS). Atua como Coordenadora de Ensino da Escola de Inteligência de Segurança Pública, da Subsecretaria de Inteligência, da Secretaria de Estado de Polícia Civil do Rio de Janeiro. E-mail: celiacveiga@gmail.com

(iD http://orcid.org/0000-0003-4932-5968 